\title{
Higher levels of psychiatric symptomatology reported by health professionals working in medical settings in Greece
}

\author{
Ioanna V Papathanasiou ${ }^{1,2^{*}}$, Dimitrios Damigos ${ }^{1}$ and Venetsanos Mavreas ${ }^{1}$
}

\begin{abstract}
Background: Psychological distress in healthcare workers may vary across different specialties. The purpose of this study was to investigate the differences in the rate of anxiety and depression between medical and mental healthcare workers.

Methods: The sample was randomly selected and consisted of 229 workers from the medical health sector and 212 from the mental health sector, aged $39.8 \pm 7.9$ years old. Health workers from University and General Hospitals from all over Greece participated in the study. The Greek version of the Symptoms Rating Scale For Depression and Anxiety (SRSDA) was used. Statistics were processed with SPSS v. 17.0.

Results: The medical health professionals showed statistically significantly higher scores in all the subscales in comparison with the mental health sector workers, independently of years serving in the department. The rates of a possible psychiatric disorder (score over cutoff points) were significantly elevated on the Beck-21, melancholy and asthenia subscales.
\end{abstract}

Conclusions: Medical healthcare workers appear to suffer from psychological distress more than their colleagues in the mental sector.

\section{Background}

The mental health state of healthcare professionals is an important issue, influencing the services they provide $[1,2]$. Healthcare workers are likely to suffer from occupational stress, which may lead to serious mental and physical health problems [3]. They exhibit high prevalence rates of social dysfunction, somatization, depression and anxiety symptoms $[4,5]$. The psychiatric domain is considered quite a stressful work environment. Mental health professionals who work in heavily stressful mental healthcare settings are frequently subject to the violent and aggressive behavior of some patients and experience anxiety about being hurt or further intimidated [6]. Burnout syndrome and depression have been found to be highly prevalent among nurses and residents in the mental health sector, especially among nursing staff [7]. However, some studies

\footnotetext{
* Correspondence: iopapathanasiou@yahoo.gr

'Department of Psychiatry, School of Medicine, University of Ioannina,

loannina, Greece

Full list of author information is available at the end of the article
}

attribute stress to organizational, rather than workrelated matters, in the psychiatric field [8,9]. In comparison to mental health workers, whose stress is well established, stress in medical workers is under-recognized and understudied. Some studies argue that medical staff appear more vulnerable to psychiatric disorders than staff in the psychiatric field $[10,11]$ and there is a clearer picture of the reasons behind psychological distress in the surgical wards and emergency departments of the medical sector. Nevertheless, stress in nurses is least studied in the area of psychology and research on comparative assessment of stress among various specialties and possible interventions is insufficient [12-14]. Nurses experience emotional situations that can cause occupational stress $[15,16]$. Physicians are also subjected to psychological disorders. They exhibit high levels of burnout and appear to have problems in the physical and social domain when compared to other healthcare workers [17-19].

Every event is subject to a cognitive evaluation by the subject who experiences it. Internal and external

\section{Ciomed Central}


resources, which include health, beliefs, responsibility, support, social skills, and material resources determine their coping strategies and stress, as Lazarus and Folkman proposed, occurs when pressure exceeds ones perceived ability to cope and when an imbalance between demands and resources is established [20]. As considerable work pressure is reported in the medical sector, the hypothesis that medical healthcare workers will report higher levels of psychological distress will be examined in the present study.

A thorough knowledge of psychological stress in healthcare workers will allow better interventions and reorganization of healthcare services, with emphasis on the sectors that are more vulnerable. The purpose of this study is to investigate and compare levels of psychological disturbances in medical and mental healthcare personnel.

\section{Materials and methods}

The sample consisted of 229 workers from the medical health sector and 212 from the mental health sector, who were all randomly selected; their mean age was $39.8 \pm 7.9$ years old. Health workers from University and General Hospitals from all over Greece participated in the study. Randomly selected hospitals from the capital city of every municipality in Greece were included in the study. Mental health as well as medical sectors of the same hospital were included. A number was assigned to every mental healthcare worker in a given hospital and a random number generator was used to produce a series of numbers equal to the desired size of each subgroup. If an individual refused to participate, the next individual was selected according to the next random number. Local ethical committees approved the study protocol. Doctors, nurses and other healthcare workers (midwives, social workers) participated in the study.

Questionnaires were sent by post to hospitals in Athens and on the islands, where a research team distributed and then collected them in other areas. A total of $45 \%$ of the questionnaires were posted and $55 \%$ were delivered in person. A preceding phone call with the directors of the departments took place in order to agree on some convenient dates (working days) for the distribution and the collection of the questionnaires. The response rate was $76 \%$ (456 out of 600 questionnaires), with $73.5 \%$ of the questionnaires (441 out of $600)$ completed without any missing data in the psychometric section and thus suitable for final evaluation. The Greek version of the Symptoms Rating Scale for Depression and Anxiety (SRSDA) questionnaire was used to evaluate health professionals' psychological distress [21]. It is based on the Beck Depression Inventory I (BDI-I) and has been expanded to include 42 items (double the number of BDI items); apart from the original $21 \mathrm{BDI}$ items, it contains several other subscales: the asthenia subscale, the melancholia inventory, the anxiety inventory, and the mania subscale.

The composition of the SRSDA subscales is as follows: (1) the 21-item Beck Depression Scale includes items 1, $8,11,13,14,17,18,19,20,21,22,23,25,26,27,28$, $29,31,32,34,41$. These are scored: $\mathrm{a}=0, \mathrm{~b}=1, \mathrm{c}=2$, $\mathrm{d}=3$. (2) The 13-item Beck Depression Scale includes items $1,8,11,13,14,19,20,22,28,29,32,34$ and 41. These are scored $a=0, b=1, c=2, d=3$. (3) The 12item melancholia subscale includes items $8,11,13,17$, 19, 20, 21, 22, 26, 29, 32 and 34. These are scored $\mathrm{a}=0$, $\mathrm{b}=1, \mathrm{c}=2, \mathrm{~d}=3$. (4) The 12-item asthenia subscale includes items $2,5,9,17,21,24,25,27,28,29,32$ and 38. These are scored: $\mathrm{a}=0, \mathrm{~b}=1, \mathrm{c}=2, \mathrm{~d}=3$. (5) The 14-item anxiety subscale includes items $3,4,5,12,15$, 17, 21, 24, 25, 27, 33, 39, 40 and 42. These are scored: a $=0, \mathrm{~b}=1, \mathrm{c}=2, \mathrm{~d}=3$. (6) The five-item mania subscale includes items which all are graded $6,10,16,30$, 37. These are scored $\mathrm{a}=-1, \mathrm{~b}=0, \mathrm{c}=0, \mathrm{~d}=+1$.

The cutoff points established for the Greek population in each subscale are as follows: BDI-21: 14, BDI-13: 7 , melancholia: 8, asthenia: 9, anxiety: 10 [21]. Regardless, all these scales are supposed to be used as screening tools rather than substitutes for an in-depth interview [22]. For the English and Greek versions of the questionnaire see: http://www.biomedcentral.com/content/ supplementary/1471-244X-3-21-S1.doc and http://www. biomedcentral.com/content/supplementary/1471-244X3-21-S2.doc, respectively.

\section{Statistics}

Descriptive statistics were initially generated for sample characteristics. Normality was checked by the Kolmogorov-Smirnov test. The results on the subscales were mixed. Some subscales exhibited marginally normal distributions (asthenia, melancholia, anxiety) while others were clearly not normally distributed (Beck-21, Beck-13, mania). As there are articles in the literature arguing that parametric tests can successfully be applied to nonnormally distributed data $[23,24]$, data was processed with parametric tests. The $t$ test was used to compare the means of SRSDA scores between the two health sectors. The $\chi^{2}$ test, along with Yates correction was used to compare rates of individuals exceeding cutoff points in SRSDA subscales. Cronbach's $\alpha$ ranged between 0.85 and 0.90 for individual SRSDA scales. More specifically: BDI-21: 0.89, BDI-13: 0.90, melancholia: 0.89, asthenia: 0.87 , anxiety: 0.88 and mania: 0.10 . Similar findings have been reported by Fountoulakis et al. [21]. As the mania scale exhibited the lowest reliability, well below 0.60 , it was excluded from the study. A general linear model with years in a department used as a covariate and the 
sector as a fixed factor was applied for Beck-21, and the melancholy and asthenia subscales were used as dependent variables. The number of years in the profession and the number of years in the department were collinear. As the analyses for both variables were not significantly different, the number of years in the department was chosen based on the assumption that years working in a given department is more predictive of an individual's present distress levels than the individual's total years of working (that is, current distress levels are more related to an individual's current work environment than to accumulated work stress or burnout, or the experience of working in the field in general). Statistics were processed with SPSS v. 17.0 (SPSS, Chicago, IL, USA). Statistical significance was set at $P=0.05$.

\section{Results}

Demographic and job features are presented in Table 1. There was no statistical difference between the two sectors regarding the participants' age (mean value 40 and 39 years for the medical and the mental health sector, respectively). The percentage of men was $25.5 \%$ ( 54 men) in the mental health sector and $21.5 \%$ (49 men) in the medical sector. In all $80 \%$ of the health workers in the medical sector were nurses, $11 \%$ doctors, $2.1 \%$ midwives and the remaining $6.9 \%$ consisted of various health professions. In the mental health sector nurses represented $63 \%$ of the sample, doctors (neurologists, psychiatrists) represented $14 \%$, and other health professionals constituted $23 \%$. The statistical analysis revealed that the workers in the medical sector had been working in each of the departments more years than their colleagues in the mental sector. Medical health professionals showed statistically significant higher scores in all the subscales in comparison with the mental sector workers, with mean values being below the cutoff scores. The cutoff points are presented as an F scale in table 2. The rates of a possible psychiatric disorder (score over cutoff points) were significantly elevated on the Beck-21, melancholy and asthenia subscales with a statistically significant difference compared to the mental health sector. The highest rate for the medical sector was on the asthenia subscale $(20.3 \%)$ and for the mental health sector on the anxiety scale (12.2\%)(Table 2). In Tables 3, 4 and 5 general linear models adjusted for the number of years in the department are presented, showing that Beck-21, melancholy and asthenia scores were related to the sector, independently of the number of years in the department.

\section{Discussion}

The data of the present study revealed that, despite the low mean values, a considerable percentage of health professionals ranging from $14 \%$ to $20 \%$ in the medical sector scored above the cutoff points. In the mental health sector the respective percentages ranged from 7.5 to $12 \%$. This study supported our hypothesis that medical healthcare workers would report higher levels of psychological distress than mental healthcare workers. This finding is in accordance with previous studies that showed that neuroticism, trait and state anxiety and depression are more prevalent in the medical group [10]. Working on surgical wards, in particular, proved to be highly stressful [11]. Another study showed that while normal levels of stress were present in most physicians, a disproportionate number of emergency physicians reported high levels of stress and depression and thoughts of abandoning their specialty [25]. Likewise, the few studies on the psychological problems of health professionals in Greece revealed high percentages of anxiety and depression in the medical sector [26,27].

Although the majority of the participants in the present study were nurses, samples were not homogenous; other specialties were included as well and the care settings were not proportionally representative. The different composition of the groups in terms of professions

Table 1 Demographic features of the sample

\begin{tabular}{|c|c|c|c|c|c|c|}
\hline \multirow[t]{2}{*}{ Demographic features } & \multicolumn{2}{|c|}{ Medical sector } & \multicolumn{2}{|c|}{ Mental health sector } & \multicolumn{2}{|c|}{ Control for mean/difference } \\
\hline & Mean & SD & Mean & SD & $t$ & $P$ value \\
\hline Age & 40 & 7.95 & 39 & 8.19 & -0.435 & 0.664 \\
\hline Years in profession & 18.34 & 7.65 & 9.31 & 7.5 & 4.683 & 0 \\
\hline Years in department & 10.52 & 7.65 & 4.07 & 4.27 & 4.04 & 0 \\
\hline Sex & N & $\%$ & & $\mathrm{~N}$ & $\%$ & \\
\hline Men & 49 & 21.4 & & 54 & 25.5 & \\
\hline Women & 180 & 78.6 & & 158 & 74.5 & \\
\hline \multicolumn{7}{|l|}{ Profession: } \\
\hline Nurses & 183 & 80 & & 134 & 63 & \\
\hline Doctors & 25 & 11 & & 29 & 14 & \\
\hline Midwives & 5 & 2.1 & & 0 & 0 & \\
\hline Other & 16 & 6.9 & & 49 & 23 & \\
\hline
\end{tabular}


Table 2 Comparative score presentation in SRSDA subscales

\begin{tabular}{|c|c|c|c|c|c|c|c|}
\hline \multirow[t]{2}{*}{ SRSDA subscales } & \multicolumn{2}{|l|}{ Mean \pm SD } & \multirow[t]{2}{*}{$P$ value } & \multirow[t]{2}{*}{ F scale } & \multicolumn{2}{|c|}{ Percentage over cutoff point } & \multirow[t]{2}{*}{$P$ value } \\
\hline & $\begin{array}{l}\text { Medical sector } \\
(\mathrm{n}=229)\end{array}$ & $\begin{array}{l}\text { Mental health sector } \\
(n=212)\end{array}$ & & & $\begin{array}{l}\text { Medical sector } \\
(\mathrm{n}=229)\end{array}$ & $\begin{array}{l}\text { Mental health sector } \\
(\mathrm{n}=212)\end{array}$ & \\
\hline Beck-21 & $8.23 \pm 6.79$ & $6.21 \pm 5.92$ & $<0.05$ & $>14$ & 14.2 & 7.5 & $<0.05$ \\
\hline Beck-13 & $3.96 \pm 4.26$ & $2.83 \pm 3.41$ & $<0.05$ & $>7$ & 14.3 & 9.9 & NS \\
\hline Melancholia & $4.91 \pm 4.44$ & $3.44 \pm 3.62$ & $<0.05$ & $>8$ & 16 & 7.5 & $<0.05$ \\
\hline Asthenia & $6.32 \pm 4.35$ & $4.56 \pm 3.98$ & $<0.05$ & $>9$ & 20.3 & 10.3 & $<0.05$ \\
\hline \multirow[t]{2}{*}{ Anxiety } & $6.36 \pm 4.72$ & $4.91 \pm 4.87$ & $<0.05$ & $>10$ & 17.6 & 12.2 & NS \\
\hline & t Test & & & & & $\chi 2$ test & \\
\hline
\end{tabular}

NS, not significant; SRSDA, Symptoms Rating Scale For Depression and Anxiety.

Table 3 General linear model for Beck-21 subscale (dependent variable) and sector/years in the department (fixed and covariate, respectively)

\begin{tabular}{|c|c|c|c|c|c|}
\hline \multirow[t]{2}{*}{ Dependent variable: Beck-21 } & \multirow[t]{2}{*}{ B } & \multirow[t]{2}{*}{$\mathbf{t}$} & \multirow[t]{2}{*}{$P$ value } & \multicolumn{2}{|l|}{$95 \% \mathrm{Cl}$ for $\mathrm{B}$} \\
\hline & & & & Lower bound & Upper bound \\
\hline Intercept & 6.784 & 9.37 & 0 & 5.414 & 8.155 \\
\hline Sector $($ medical $=1)$ & 2.412 & 3.438 & 0.001 & 1.033 & 3.791 \\
\hline Years in the department & -0.099 & -0.987 & 0.324 & -0.296 & 0.098 \\
\hline
\end{tabular}

Table 4 General linear model for asthenia subscale (dependent variable) and sector/years in the department (fixed and covariate, respectively)

\begin{tabular}{llllll}
\hline Dependent variable: asthenia & B & $\mathbf{t}$ & P value & \multicolumn{2}{l}{$\mathbf{9 5 \% \text { Cl for B }}$} \\
\cline { 5 - 6 } & & & & Lower bound & Upper bound \\
\hline Intercept & 4.263 & 10.004 & 0 & 3.425 & 5.1 \\
Sector (medical $=1$ ) & 1.959 & 4.568 & 0 & 1.116 & 2.801 \\
Years in the department & -0.041 & -0.061 & 0.509 & -0.161 & 0.08 \\
\hline
\end{tabular}

raises the question of whether the observed differences between the sectors are due to requirements of the sector or to their different composition. As many specialties were included and representation was not proportional for every health unit, it was difficult to control such variables and make any conclusions about their practical implications. While in Greece there are no autonomous emergency departments (ED), doctors and nurses from the clinics serve in EDs periodically. Unfortunately, information regarding working in the ED during the time of this survey was not obtained. Moreover, many participants did not fill in some job and demographic characteristics and so in-depth linear regression analysis could not be carried out. A further study, including proportionate samples of greater numbers from all care sectors within the medical and mental health area, could reveal particularly vulnerable groups and provide the appropriate explanation for the above findings. Emphasis should be placed on nursing shortages, nursing motivation and job satisfaction. The nursing shortage in Greece has caused nurses to work long and continuous shifts, taking up high levels of workload. Subsequently, further research into stress levels and distress among nurses might be especially warranted. A great deal of paperwork and bureaucracy add extra job demands. Years of experience and coping

Table 5 General linear model for melancholia subscale (dependent variable) and sector/years in the department (fixed and covariate, respectively)

\begin{tabular}{|c|c|c|c|c|c|}
\hline \multirow[t]{2}{*}{ Dependent variable: melancholia } & \multirow[t]{2}{*}{ B } & \multirow[t]{2}{*}{$\mathrm{t}$} & \multirow[t]{2}{*}{$P$ value } & \multicolumn{2}{|l|}{$95 \% \mathrm{Cl}$ for $\mathrm{B}$} \\
\hline & & & & Lower bound & Upper bound \\
\hline Intercept & 3.979 & 8.835 & 0 & 5.689 & 9.696 \\
\hline Sector $($ medical $=1)$ & 1.857 & 4.098 & 0 & 0.966 & 2.748 \\
\hline Years in the department & -0.101 & -1.564 & 0.118 & -0.229 & 0.026 \\
\hline
\end{tabular}


mechanisms are factors that should be taken into account as they are related to emotional competency. Identifying the multiple dimensions of stress in various clinical settings would allow for meaningful interventions.

\section{Conclusions}

Medical healthcare workers appear to suffer from psychological distress more than their colleagues in the mental health sector. Evidence of high distress levels in the medical sector may help draw attention to this issue and trigger the appropriate interventions. A careful study of the work environment would be helpful in determining the factors responsible for psychological disturbances in healthcare professionals in the various care settings in Greece, and would be a starting point for further changes.

\section{Author details}

'Department of Psychiatry, School of Medicine, University of loannina, loannina, Greece. ${ }^{2}$ Department of Nursing, Technological Educational Institute of Larissa, Larissa, Greece.

\section{Authors' contributions}

IVP participated in study design, data collection and drafted the manuscript. DD participated in the design of the study and helped to draft the manuscript. VM conceived the study and critically revised it.

\section{Competing interests}

The authors declare that they have no competing interests.

Received: 10 February 2011 Accepted: 19 October 2011

Published: 19 October 2011

\section{References}

1. Kikuchi Y, Nakaya M, Ikeda M, Narita K, Takeda M, Nishi M: Effort-reward imbalance and depressive state in nurses. Occup Med (Lond) 2010, 60:231-233.

2. Tabolli S, lanni A, Renzi C, Di Pietro C, Puddu P: Job satisfaction, burnout and stress amongst nursing staff: a survey in two hospitals in Rome. $G$ Ital Med Lav Ergon 2006, 28:49-52.

3. Marine A, Ruotsalainen J, Serra C, Verbeek J: Preventing occupational stress in healthcare workers. Cochrane Database Syst Rev 2006, 18: CD002892.

4. Shanafelt TD, Sloan JA, Habermann TM: The well-being of physicians. Am Med 2003, 114:513-519.

5. Weinberg A, Creed F: Stress and psychiatric disorder in healthcare professionals and hospital staff. Lancet 2000, 355:533-537.

6. Currid T: Experiences of stress among nurses in acute mental health settings. Nurs Stand 2009, 23:40-46.

7. Halayem-Dhouib S, Zaghdoudi L, Zremdini R, Maalej I, Ben Béchir M Labbène R: Burnout among mental health professionals: a Tunisian experience. Rev Epidemio/ Sante Publique 2010, 58:403-408.

8. Ryan D, Quayle E: Stress in psychiatric nursing: fact or fiction? Nurs Stand 1999, 14:32-35

9. Pinikahana J, Happell B: Stress, burnout and job satisfaction in rural psychiatric nurses: a Victorian study. Aust J Rural Health 2004, 12:120-125.

10. Dudley $M$, Langeluddecke $P$, Tennant C: Psychological dysfunction in psychiatric and general nurse trainees. J Psychosom Res 1988, 32:373-381.

11. Yamashita K: Mental health of nurses-2 years follow-up. Nihon Kango Kagakkaishi 1997, 17:64-68.

12. Pryjmachuk S, Richards DA: Mental health nursing students differ from other nursing students: Some observations from a study on stress and coping. Int J Ment Health Nurs 2007, 16:390-402.
13. Fagin L, Carson J, Leary J, De Villiers N, Bartlett H, OMalley P, West M, McElfatrick S, Brown D: Stress, coping and burnout in mental health nurses: findings from three research studies. Int J Soc Psychiatry 1996, 42:102-111.

14. Dosani S: Review: stress is a problem for mental health nurses but research on interventions is insufficient. Evid Based Ment Health 2003, 6:126

15. Ben-Zur H, Michael K: Burnout, social support, and coping at work among social workers, psychologists, and nurses: the role of challenge/ control appraisals. Soc Work Health Care 2007, 45:63-82.

16. Salomé GM, Martins MF, Espósito VH: Feelings of nursing professionals who work in emergency units. Rev Bras Enferm 2009, 62:856-862.

17. Pompili M, Innamorati M, Narciso V, Kotzalidis GD, Dominici G, Talamo A, Girardi P, Lester D, Tatarelli R: Burnout, hopelessness and suicide risk in medical doctors. Clin Ter 2010, 161:511-514.

18. Tzeng DS, Chung WC, Fan PL, Lung FW, Yang CY: Psychological morbidity, quality of life and their correlations among military health care workers in Taiwan. Ind Health 2009, 47:626-634.

19. Røvik JO, Tyssen R, Hem E, Gude T, Ekeberg O, Moum T, Vaglum P: Job stress in young physicians with an emphasis on the work-home interface: a nine-year, nationwide and longitudinal study of its course and predictors. Ind Health 2007, 45:662-671.

20. Folkman S, Lazarus RS: Personal control and stress and coping processes: a theoretical analysis. Personal Social Psychol 1984, 46:839-852.

21. Fountoulakis KN, lacovides A, Kleanthous S, Samolis S, Gougoulias K, S Kaprinis $G$, Bech P: The Greek translation of the symptoms rating scale for depression and anxiety: preliminary results of the validation study. BMC Psychiatry 2003, 10:21

22. Zung WW, Richards $C B$, Short MJ: Self-rating depression scale in an outpatient clinic. Further validation of the SDS. Arch Gen Psychiatry 1965, 13:508-515.

23. Vickers AJ: Parametric versus non-parametric statistics in the analysis of randomized trials with non-normally distributed data. BMC Med Res Methodol 2005, 5:35.

24. Zimmerman DW: Statistical significance levels of nonparametric tests biased by heterogeneous variances of treatment groups. J Gen Psychol 2000, 127:354-364

25. Gallery ME, Whitley TW, Klonis LK, Anzinger RK, Revicki DA: A study of occupational stress and depression among emergency physicians. Ann Emerg Med 1992, 21:58-64.

26. Tselebis A, Gournas G, Tzitzanidou G, Panagiotou A, Ilias I: Anxiety and depression in Greek nursing and medical personnel. Psychol Rep 2006 99:93-96.

27. Humpel N, Caputi P: Exploring the relationship between work stress, years of experience and emotional competency using a sample of Australian mental health nurses. J Psychiatr Ment Health Nurs 2001, 8:399-403.

doi:10.1186/1744-859X-10-28

Cite this article as: Papathanasiou et al: Higher levels of psychiatric symptomatology reported by health professionals working in medical settings in Greece. Annals of General Psychiatry 2011 10:28

\section{Submit your next manuscript to BioMed Central and take full advantage of:}

- Convenient online submission

- Thorough peer review

- No space constraints or color figure charges

- Immediate publication on acceptance

- Inclusion in PubMed, CAS, Scopus and Google Scholar

- Research which is freely available for redistribution 